\title{
Disasters, pandemics and mental health
}

\author{
Clare Pain MD DSc, Ruth Lanius MD PhD
}

Cite as: CMAJ 2020 July 13;192:E803. doi: 10.1503/cmaj.200736

CMAJ Podcasts: author interview at https://soundcloud.com/cmajpodcasts/200736-five

\section{1} Mental distress is common in public health emergencies

After a disaster, population rates of psychological distress tend to double or triple. Acute-phase reactions and disorders generally resolve within a year; however, there is considerable variation in recovery times. ${ }^{1}$ Subsequent to the accident at the Fukushima Daiichi Nuclear Power Plant, for example, $6 \%$ of people affected remained severely distressed 3 years after the incident. ${ }^{2}$

\section{2}

\section{Prolonged exposure to war and conflict increases the} prevalence of mental illness

Among people who have experienced war in the previous 10 years, $21 \%$ have a mental health disorder, and $9 \%$ meet standardized criteria for moderate or severe mental illness. ${ }^{3}$ However, focusing exclusively on psychiatric disorders overlooks a range of health risk behaviours, such as substance misuse, which is associated with increased domestic violence and accidents. ${ }^{1}$

\section{3} Clinicians can focus their attention on those at risk for mental health disorders

Much of the initial distress in a population is self-limiting. Risk factors for prolonged and more intense distress include a pre-existing psychiatric disorder, poverty and inadequate housing. ${ }^{4}$ Subjective sleep insufficiency, substance overuse and poor social support are associated with more severe psychological distress. ${ }^{1,2}$

\section{Misinformation can contribute to distress}

Without access to relevant and accurate information about the disaster there is increased community distress, leading to a reduction in positive health behaviours, which can strain public health systems. ${ }^{1}$

\section{Safety and security are first priorities}

Addressing personal, family and workplace safety is fundamental to a competent response to disaster. Maintaining a regular schedule for sleep, exercise and eating helps regulate emotions. Connecting at both the individual and community level is key to optimizing health. ${ }^{5}$

\section{References}

1. Morganstein JC, Ursano RJ. Ecological disasters and mental health: causes, consequences, and interventions. Front Psychiatry 2020;11:1.

2. Oe M, Maeda M, Nagai M, et al. Predictors of severe psychological distress trajectory after nuclear disaster: evidence from the Fukushima Health Management Survey. BMJ Open 2016;6:e013400.

3. Charlson F, van Ommeren M, Flaxman A, et al. New WHO prevalence estimates of mental disorders in conflict settings: a systematic review and meta-analysis. Lancet 2019;394:240-8.

4. LeardMann CA, Smith B, Ryan MA. Do adverse childhood experiences increase the risk of postdeployment posttraumatic stress disorder in US marines? BMC Public Health 2010; 10:437.

5. The psychological needs of healthcare staff as a result of the coronavirus pandemic [news]. Leicester (UK): The British Psychological Society; 2020.

\section{Competing interests: None declared.}

This article was solicited and has been peer reviewed.

Affiliations: Department of Psychiatry (Pain), University of Toronto; Psychological Trauma Program (Pain), Mount Sinai Hospital, Toronto, Ont.; Department of Psychiatry (Lanius), Western University, London, Ont.

Correspondence to: Clare Pain, clare.pain@sinaihealth.ca

CMAJ invites submissions to "Five things to know about ..." Submit manuscripts online at http://mc. manuscriptcentral.com/cmajeditor note 